ORIGINAL ARTICLE

\title{
Comparison of three preventive methods in order to reduce the incidence of ankle inversion sprains among female volleyball players
}

\section{Stasinopoulos}

Br J Sports Med 2004;38:182-185. doi: 10.1136/bjsm.2002.003947

Background: Ankle sprains are the most common form of acute injury in volleyball. A prevention programme consisting of technical training, proprioceptive training, and external support was previously designed to reduce the rate of ankle sprains in volleyball players.

Objective: To investigate which of these three interventions is the most effective in preventing ankle sprain in female volleyball players.

Methods: Participants were 52 players who suffered ankle sprains during the season 1998-1999. They were divided randomly into three preventive groups: group $1(n=18)$ followed the technical training programme; group $2(n=17)$ followed the proprioceptive programme; group $3(n=17)$ used orthosis. The

Correspondence to:

D Stasinopoulos, Physical

Therapist, Centre of

Rheumatology and

Rehabilitation, 16

Orphanidou St, Athens

11141, Greece;

d_stasinopoulos@

yahoo.gr

Accepted 17 March 2003 players followed their respective programmes for the whole of the 1999-2000 season. Data were collected at the end of the season.

Results: The three preventive strategies were all effective in preventive further ankle sprain. Technical training was slightly more effective than the other two methods. Orthosis was not effective in athletes who had suffered ankle sprains more than three times during their careers. Under those circumstances, technical training and proprioceptive training were equally effective at preventive further sprains.

Conclusions: Technical training and proprioceptive training are effective methods of preventing ankle sprain in volleyball players who have suffered this injury four or more times during their career. Orthosis appears effective only in players with fewer than four previous sprains.
$\mathrm{V}$ olleyball is one of the most popular sports in the world, and the International Volleyball Federation represents about 150 million players in approximately 170 countries. ${ }^{1}$ The injury incidence is between 1.7 and 4.2 per 1000 hours of play, ${ }^{2-6}$ and it is the fourth most common source of sports injuries. ${ }^{6}$

Ankle inversion sprains (for the purpose of the study ankle inversion sprains are referred to as ankle sprains) are the most common acute injuries in volleyball. ${ }^{2-8}$ Studies have shown that the injury rate in volleyball is lower than in other team sports such as soccer and basketball. Presumably this difference can be attributed to the non-contact nature of the game, as players from opposing teams are separated by the net. However, the rate of acute ankle sprains in volleyball is 0.9 per 1000 player hours, which is comparable to that found in contact sports such as soccer and basketball. ${ }^{2}{ }^{4} 9$

The mechanisms of ankle sprains in volleyball have been examined in detail. These injuries mainly occur when a player lands on the foot of an opponent in the conflict zone under the net (blocker on attacker or vice versa), or a player lands on the foot of a team-mate when landing from a two man block. ${ }^{2-9}$ Previous ankle injury is an additional risk factor, as there is a marked increase in injury rate during the first six to 12 months after an ankle sprain. ${ }^{4}$ Finally, another important risk factor is when an athlete resumes playing while still having ongoing symptoms or with inadequate rehabilitation..$^{2-4} 6$

As ankle sprains are such common injuries in volleyball, Bahr and his colleagues ${ }^{10}$ suggested four main interventions to reduce their occurrence. These were:

- rule changes to reduce the conflict zone under the net where an attacker may land on a blocker's foot or vice versa;
- use of tape or ankle braces as external ankle protection;

- specific technical training on take off and landing technique during attack and two man blocks;

- proprioceptive training after an ankle injury.

A change of rules so that there is a safety zone of $5 \mathrm{~cm}$ under the net where players are not allowed to step or land should reduce the risk of a player landing on the feet of an opponent. However, such a rule change may cause an unacceptable number of game interruptions because of footfaults on the net line. ${ }^{10}$ In fact, in a test during tournament play with a stricter net line violations rule, $8.4 \%$ of 1335 rallies were terminated because of net line violations, compared with only $0.3 \%$ of 1768 rallies observed during play with the regular line. ${ }^{10}$ Thus a more restrictive rule change cannot be recommended because of the negative effects on the flow of the game. Following this finding, Bahr et al omitted their first intervention, reducing the number to three.

External support (taping/orthosis) is the most common preventive method among athletes, and many studiesespecially laboratory investigations and some clinical studies-have been done to establish its effectiveness. Randomised clinical trials have reported that orthosis reduces the incidence of ankle sprains in previously sprained ankles, but not in previously uninjured ankles. ${ }^{11-13}$ The reason for this differential effect is not clear. ${ }^{12}$ One explanation could be that proprioception defects occur after an ankle sprain, and Surve et al postulated that the main effect of orthosis is to improve the proprioceptive function of a previously injured ankle rather than to provide mechanical support alone. ${ }^{12}$ Additional biomechanical and clinical research is needed to determine the exact mechanisms whereby prophylactic ankle stabilisers are effective in reducing ankle injuries. The use of external 
support should be recommended for a period of 12 months after an ankle sprain, because the risk of reinjury is increased during the first year and the ligaments need about a year to heal properly and to regain their normal strength and proprioceptive ability after an ankle injury. ${ }^{4}$

Improvements in technique could be an important preventive measure and need to be taught to players by their coaches. Poor technique may result in injuries in sports. If athletes improve their technique the rate of injuries is reduced. Learning the correct technique for a sport takes time. As athletes gain experience, their technique improves. Thus the frequency of injuries may be increased at the start of their careers. The technique of an athlete may cause injuries as well as preventing them. We have found only one prospective study, by Ekstrand and Troop ${ }^{14}$ in amateur Swedish soccer players, which showed that specific technical training can reduce the rate of ankle sprains.

Proprioceptive training has been used to prevent ankle sprains since this form of prophylaxis was first proposed by Freeman et al. ${ }^{15}$ Proprioceptive training often involves the use of devices such as tilt boards, ankle disks, balance boards, and so on, which demand use of the muscles that pronate and supinate the feet. ${ }^{16-18}$ Sheth et al believe that it is a unique method of training, because it stimulates multiple planes of ankle movement on a weight bearing foot, an activity that would occur infrequently otherwise. ${ }^{19}$ In a clinical study, Troop et al reported a decreased rate of ankle sprains in Swedish soccer players after an ankle disk training programme of 10 weeks. ${ }^{13}$

Bahr and his colleagues ${ }^{10}$ used two of their three preventive measures (a proprioceptive training programme and a specific technical training programme) to reduce the rate of ankle sprains in amateur Norwegian volleyball players. They did not use external support because it is only effective in players with previous ankle injuries, and in their study the participating players had no previous ankle sprains. In the proprioception programme the players were taught how to use an ankle balance board. In the technical training, they were coached on take off and landing technique during attack. Players were coached to do a quick and long final approach step and to jump straight up to hit the ball, instead of forward, so that they would not land on the centre line under the net. Furthermore, players were coached on side to side movement and take off technique for one man and two man blocks. Bahr et al found that this programme reduced the rate of ankle sprains by about $50 \%$, from 0.9 per 1000 player hours during the season 1992-1993 to 0.5 per 1000 player hours during the season 1994-1995. Unfortunately, they could not establish with certainty the degree to which the two elements of the prevention programme-technical training and proprioception training-each contributed to the overall results. Further studies are needed to identify the effect of each programme component.

The present study was designed to fill this gap in the research. The aim of this study was to investigate which of the three intervention strategies-external support, proprioceptive training, and specific technical training-is the most effective in preventing ankle sprains in female volleyball players with a history of previous injuries of this type.

\section{METHODS}

The sample population for the study was intended to include all competitors who played in teams in the second division of the women's Greek National league in the season 1998-1999 and suffered ankle sprains sufficient to cause a player to miss three or more consecutive days immediately after sustaining the injury. ${ }^{2} 812$

The Greek Volleyball Federation consists of male and female professional and amateur teams. Professional women's teams are separated into three divisions according to their level of performance. The second division consists of 10 teams and the level of performance is very good but not "elite".

The coaches of the teams in this division were contacted and the purpose of the study explained to them. All the coaches wanted their teams to participate in the study. The coaches reported 52 injuries. No player reported more than one ankle injury during the season. The physiotherapistresearcher contacted the players and gained information about previous ankle sprains and the adequacy of rehabilitation after the ankle injury. Only players who had adequate rehabilitation after their injury and returned to the sport free of ongoing symptoms were included in the study.

Players $(n=52)$ were divided at random, using random number tables, into the three prevention groups. Players were also grouped according to how many times they had suffered ankle sprains during their careers.

A physiotherapist visited the players at the beginning of the season to inform them which prevention programme they would follow and to give them instructions on how to follow it.

The first group $(n=18)$ followed a prevention programme that consisted of specific technical training on take off and landing technique during attack and two man blocks. Players were coached to do a quick and long final approach step and jump straight up to hit the ball, instead of forward, so that they would not land on the centre line under the net. Players were also coached on side to side movement and take off technique for one man and two man blocks. This programme was the same as described by Bahr et al. ${ }^{10}$

The second group $(n=17)$ followed proprioceptive training using the balance board each day, thirty minutes a day for the whole season. Details of the proprioceptive training are to be found in papers by Bahr et al and Troop et al. ${ }^{10}{ }^{13}$

In the third group $(\mathrm{n}=17)$, the players used Sport-Stirrup orthosis. Players were advised to wear the orthosis for each game and during each training session throughout the season. The physiotherapist showed the players how to wear the orthosis at the first visit and after this the player had no difficulty in putting it on herself. The characteristics of the Sport-Stirrup orthosis are well known from numerous previous reports.

The players followed the prevention programme for the whole of the 1999-2000 season. Data were collected at the end of the season. The physiotherapist contacted all the players to find out whether or not they had been injured again.

Informed consent was obtained from all the players for their participation, and they were free to withdraw from the study if they wished.

\section{RESULTS}

Table 1 shows the characteristics of the players who participated in the study.

Table 2 shows how many times the players had suffered ankle sprain during their careers. Of six players (12\%) who had adequate rehabilitation after ankle sprains, five had suffered a single sprain and the other player had suffered two sprains during her career.

Of 18 players who followed the first prevention programme (technical training), four $(22 \%)$ had suffered ankle sprain once, four $(22 \%)$ twice, four $(22 \%)$ three times, and four $(22 \%)$ four times. Two ( $12 \%)$ had suffered ankle sprain more than four times.

Of 17 players who followed the second prevention programme (proprioceptive training), four $(23 \%)$ had suffered ankle sprain once, four (23\%) twice, four $(23 \%)$ three 
Table 1 Players' characteristics

\begin{tabular}{lllllll}
\hline $\mathbf{n}$ & Age (years) & Height $(\mathrm{cm})$ & Weight $(\mathbf{k g})$ & $\begin{array}{l}\text { Experience } \\
\text { (years) }\end{array}$ & $\begin{array}{l}\text { Training/week } \\
\text { (hours) }\end{array}$ & Matches/year \\
\hline 52 & $23(3)$ & $180.6(4.50)$ & $69.28(5.59)$ & $10.4(3.12)$ & $10.28(2.39)$ & $29(9.33)$ \\
\hline \multicolumn{2}{l}{ Values are mean (SD). }
\end{tabular}

times, and three (18\%) four times. Two (12\%) had suffered ankle sprain more than four times.

Of 17 players who followed the third prevention programme (orthosis), four $(23 \%)$ had suffered ankle sprain once, four $(23 \%)$ twice, four $(23 \%)$ three times, and three ( $18 \%)$ four times. Two (12\%) had suffered ankle sprain more than four times.

Of the 18 players who followed the first prevention programme, two (12\%) suffered ankle sprain the next season; of the 17 players who followed the second prevention programme, three (18\%) suffered ankle sprain the next season; and of the 17 players who followed the third prevention programme, six (35\%) suffered ankle sprain the next season.

Of two players who followed the first prevention programme and had ankle sprain, one had suffered ankle sprain four times during her career (one of the four players who had suffered ankle sprains four times during their careers and followed this prevention programme), and the other player had suffered ankle sprain more than four times during her career (one of the two players who had suffered ankle sprains more than four times during their career and followed this prevention programme).

Of three players who followed the second prevention programme and had ankle sprain, one had suffered ankle sprain three times during her career (one of the four players who had suffered ankle sprains three times during their career and followed this prevention programme), one player had suffered ankle sprain four times during her career (one of the three players who had suffered ankle sprains four times during their career and followed this prevention programme), and one had suffered ankle sprain more than four times during her career (one of the two players who had suffered ankle sprains more than four times during their career and followed this prevention programme).

Of six players who followed the third prevention programme and had ankle sprain, one had suffered ankle sprain three times during her career (one of the four players who had suffered ankle sprains three times during their career and followed this prevention programme), three players had suffered ankle sprain four times during their careers (all three of the players who had suffered ankle sprains four times during their career and followed this prevention programme), and two had suffered ankle sprain more than four times during their careers (both of the two players who had suffered ankle sprains more than four times during their careers and followed this prevention programme).

Table 2 Frequency of ankle sprain in volleyball players during their careers

\begin{tabular}{ll}
\hline Players & Number of sprains \\
\hline $12(23 \%)$ & 1 \\
$12(23 \%)$ & 2 \\
$12(23 \%)$ & 3 \\
$10(19 \%)$ & 4 \\
$6(12 \%)$ & $>4$ \\
\hline
\end{tabular}

\section{DISCUSSION}

This study tried to fill the gap which arose after the study by Bahr et al ${ }_{1}^{10}$ who could not establish with certainty the degree to which the elements in their prevention programme each contributed to the overall result. In the present study I tried to identify the effects of each preventive strategy in players with a history of previous ankle sprain.

The three preventive strategies were all effective at reducing the rate of ankle sprains among female volleyball players. The most effective prevention programme was technical training and the least effective was the SportStirrup orthosis. Further analysis of the results showed that the three prevention programmes were all effective at reducing the incidence of ankle sprains in players who had suffered sprains once and twice during their careers. However, orthosis was not an effective preventive strategy in players who had suffered four or more sprains during their careers. Thus the medical team now does not recommend the use of orthosis as a preventive method in players who have suffered ankle sprains four times or more, because it appears ineffective-all the players who used the orthosis who had suffered ankle sprain four times or more during their careers had further ankle sprains. Generally, players who have had more than three previous ankle sprains need to use one of the other two methods-technical training or proprioceptive training. Players who have had three ankle sprains during their career can use any of the three preventive methods, but technical training was slightly more effective than the other two methods.

These three preventive methods are also effective in reducing the rate of ankle sprains in other sports. The results of the study be Ekstrand and Troop, ${ }^{14}$ in which they used technical training as a prevention strategy in soccer player, were similar to the results of our study. Troop et al also used proprioceptive training as a prevention strategy, ${ }^{13}$ with similar results to our study. Sitler et al, ${ }^{11}$ Surve et al, ${ }^{12}$ and Troop et $\mathrm{l}^{13}$ all used orthosis as a prevention strategy in their studies, again with results similar to ours.

It was strange that only six of 52 injured players followed a rehabilitation programme after their injury. In these cases the medical team apparently did not inform the players that inadequate rehabilitation is one of the reasons for the high frequency of reinjury. Further studies are needed to investigate the level of knowledge of the medical teams which work with volleyball teams performing at this level.

As the players belonged to the second division of Greek volleyball, where the level of performance is very good and the players all have more than 10 years' experience, the physiotherapist expected that they would have good technique, and that this would protect them from injuries. Unfortunately, it seems that they were not taught the correct technique, as in the players who followed the technical training the incidence of ankle sprains was reduced. Technical training is the role of the coach and not of the physiotherapist, so the physiotherapist wondered whether the coaches were fulfilling their role adequately in this respect. Future studies are needed to investigate the level of knowledge of coaches who work with teams performing at this level. 
Our study had some limitations. As I visited the players only once at the start of the season, I had no information about how the players complied with the advice and information offered them. The results would probably have been better if regular reinforcement had been given. Moreover, it was possible that the players' interest in the study and their willingness to participate actively may have changed during the season when the study was conducted. Finally, I did not carry out any biomechanical assessments. As biomechanical factors are possible risk factors in players with recurrent ankle sprains, biomechanical assessment might be of fundamental importance in preventing ankle sprains. Future studies will not have these limitations.

Further studies are needed to investigate the effectiveness of these three preventive strategies in male volleyball players, as well as among teams (men and women) in the first division, in which the level of performance is elite. A comparative study among male and female volleyball players needs to be carried out in order to determine the effectiveness of the three preventive strategies in the two sexes, as male volleyball playing is based on strength while female playing is based on technique. Studies are also needed to find out which of the prevention strategies is most effective in players with no history of ankle sprain.

\section{Conclusions}

All three preventive strategies were effective in athletes who had suffered ankle sprain once or twice only during their career. In athletes who had suffered ankle sprain three times during their career, technical training was slightly more effective than the other two preventive methods. Orthosis was not effective in athletes who had suffered ankle sprain more than three times during their career. In the latter case, technical training and proprioceptive training were equally effective in preventing further sprains.

\section{REFERENCES}

1 Ferretti A, Papandrea P, Conteduca F. Knee injuries in volleyball. Sports Med 1990;10:132-8.

2 Aagaard H, Jorgensen U. Injuries in elite volleyball. Scand J Med Sci Sports 1996:6:228-32.

3 Aagaard $\mathrm{H}$, Scavenius $M$, Jorgensen $U$. An epidemiological analysis of the injury pattern in indoor and beach volleyball. Int I Sports Med 1997; 18:217-21.

4 Bahr R, Bahr IA. Incidence of acute volleyball injuries: a prospective cohort study of injury mechanisms and risks factors. Scand J Med Sci Sports 1997; 7:166-71.

5 Schafle DM, Requa KR, Patton LW, et al. Injuries in the 1987 National Amateur Volleyball tournament. Am J Sports Med 1990;18:624-31.

6 Solgard L, Nielsen BA, Moller-Madsen B, et al. Volleyball injuries presenting in casualty: a prospective study. Br J Sports Med 1995;15:200-3.

7 Gerberich GS, Luhmann S, Finke C, et al. Analysis of severe injuries associated with volleyball activities. Physician Sports Med 1987;15:75-9.

8 Watkins J, Green NB. Volleyball injuries: a survey of injuries of Scottish National league male players. Br J Sports Med 1992;26:135-7.

9 Bahr R, Karlsen R, Lian O, et al. Incidence and mechanisms of acute ankle inversion injuries in volleyball. A retrospective cohort study. Am J Sports Med 1994;22:595-600.

10 Bahr R, Lian O, Bahr IA. A twofold reduction in the incidence of acute ankle sprains in volleyball after the introduction of an injury prevention program: a prospective cohort study. Scand J Med Sci Sports 1997:7:172-7.

11 Sitler M, Ryan J, Wheeler B. The efficacy of a semirigid ankle stabilizer to reduce acute ankle injuries in basketball. Am J Sports Med 1994;22:454-61.

12 Surve I, Schwellnus PM, Noakes T, et al. A fivefold reduction in the incidence of recurrent ankle sprains in soccer players using the sport stirrup orthosis. Am J Sports Med 1994;22:601-6.

13 Troop H, Askling C, Gillquist J. Prevention of ankle sprains. Am J Sports Med 1985;13:259-62.

14 Ekstrand J, Troop H. The incidence of ankle sprains in soccer. Foot Ankle 1990;11:141-4.

15 Freeman AM, Dean RM, Hanham NI. The etiology and prevention of functional instability of the foot. J Bone Joint Surg Br 1965;47B:678-85.

16 Diamond EJ. Rehabilitation of ankle sprains. Clin Sports Med 1989;8:877-90.

17 Milch D. Rehabilitation exercises following inversion ankle sprains. J Am Podiatry 1986;76:577-86.

18 Robbins S, Waked E. Factors associated with ankle injuries. Sports Med 1998;25:63-72.

19 Sheth P, Yu B, Laskowski R, et al. Ankle disk training influences reaction time of selected muscles in a simulated ankle sprain. Am J Sports Med 1997;22:538-43. 